\title{
Pandemic and progressivity
}

\author{
Alexander Klemm ${ }^{1}$ iD Paolo Mauro ${ }^{1}$
}

Accepted: 27 August 2021 / Published online: 18 November 2021

(c) International Monetary Fund, under exclusive licence to Springer Science+Business Media, LLC, part of Springer Nature 2021

\begin{abstract}
Based on a survey of 2500 US adults, we show that serious illness or job losses caused by the COVID-19 pandemic increase support for temporary progressive levies or structural progressive tax reform, controlling for socioeconomic and demographic characteristics. People who reveal preferences for spending items (more on police, military, border protection; less on education, health, environment) that are associated with communitarian (rather than universalist) moral perspectives show generally weaker support for progressive reforms, but more of them change their views following personal experience. The results are consistent with previous findings that economic upheavals can mold individuals' views on policy matters.
\end{abstract}

Keywords Solidarity taxes $\cdot$ Surcharges $\cdot$ Surveys $\cdot$ Attitudes $\cdot$ Progressivity $\cdot$ Tax reform

JEL Classification $\mathrm{H} 24 \cdot \mathrm{H} 23 \cdot \mathrm{H} 12$

\section{Introduction}

The impact of the COVID-19 pandemic on both inequality and the state of the public finances has rekindled interest in understanding people's attitudes toward policies that affect the distribution of income or access to basic public services. Such policies include, for example, taxation and its degree of progressivity, and the composition of public expenditures. The pandemic has also given renewed prominence to the question whether directly experiencing major economic upheavals changes people's attitudes toward public policies. To address these questions, this paper reports the results of a survey of about 2500 US individuals in October 2020 that elicits respondents' views on potential changes in taxation and on who should bear the burden, as well as which types of expenditures could be reduced or increased. The

Alexander Klemm

aklemm@imf.org

1 International Monetary Fund, Washington, DC, USA 
survey explores the impact of personal experiences stemming from the pandemicserious illness or job losses_-in shaping respondents' attitudes toward these fiscal policy choices. The survey was undertaken at a time when a significant share of US residents had already been gravely affected by COVID-19, and the issue was among the most salient during the contentious run-up to the November 2020 election.

This is the first survey-based analysis to gauge people's attitudes toward tax and other fiscal policy choices in the context of the pandemic, relating such attitudes to respondents' personal experience with the pandemic, moral perspectives, and demographic characteristics. ${ }^{1}$ It builds on previous studies that have advanced the understanding of people's attitudes toward taxation (Stantcheva, 2020) ${ }^{2}$ and public expenditure choices (Enke, 2020; Enke et al., 2020). Focusing on a US contextwhere previous studies have established certain regularities in the data-allows us to circulate a more concise survey and makes it easier to relate the results in the present paper to findings obtained in a pre-pandemic context by other researchers.

The objective of the survey was to elicit people's views in favor of or against the following:

- Increasing taxation as a way of financing additional expenditures caused by the pandemic and the need to foster the economic recovery, by introducing a temporary tax explicitly linked to this goal;

- Permanently increasing the degree of progressivity of taxation; ${ }^{3}$

- Reducing or further increasing various expenditure categories, such as health, education, military, etc. This is of interest in its own right ${ }^{4}$ in addition, based on results by Enke (2020) and Enke et al. (2020), it provides insight into each respondent's moral perspectives (see below).

Moreover, for some questions, the survey used different labels ("contribution" versus "tax") and made appeal to different justifications ("solidarity" versus "financing the recovery") to gain insights into the effectiveness of different ways of

\footnotetext{
${ }^{1}$ Previous analyses of the determinants of individual attitudes toward progressive taxation have generally found that fairness considerations and beliefs regarding the role of effort for economic success are more important than an individual's financial interest (Alesina \& Giuliano, 2009; Hennighausen \& Heinemann, 2014).

${ }^{2}$ In her pre-pandemic survey of US individuals, Stantcheva (2020, Fig. 19, p. 53) found that one quarter of Republicans and three quarters of Democrats supported higher income taxes on the rich to fund investment. If used to fund programs for low incomes, support stood above one half for both groups.

${ }^{3}$ Participants were asked whether they favored an increase in the progressivity of the tax system. In interpreting the results, it is worth recalling previous findings that respondents make systematic errors in the estimation of tax rates and tend to underestimate the existing progressivity of the system (Gideon 2017).

${ }^{4}$ Forenmy et al. (2020) report early evidence that the pandemic caused a sizable increase in preferred spending on health. Rees-Jones et al. (2020) find that support for health spending and social safety nets is positively associated with (a) COVID-19 deaths and infections in the respondent's county, (b) the pandemic-induced change in the unemployment rate in the respondent's county, and (c) survey elicitations of the respondent's perceptions of COVID-19's consequences.
} 
presenting policy packages and to understand what resonates best with different segments of the respondents.

The key results are as follows:

- Attitudes regarding taxation, and progressive taxation in particular, are more favorable among people who hold "universalist" rather than "communitarian" moral perspectives, elicited in the survey through questions about spending priorities.

- Respondents who have experienced serious illness or job loss caused by the COVID-19 pandemic, or who personally know someone who has, favor progressive taxation to a greater extent than others in the sample. More people with communitarian perspectives are likely to shift their views in favor of progressive taxation as a result of severe personal exposure to illness or job loss due to the pandemic.

- Support for a temporary levy seems relatively insensitive to variation in labels for such levy, with a marginally statistically significant preference for the term "COVID-19 recovery contribution."

The extent to which personal experiences can affect people's attitudes toward public policies in general and preferences regarding redistribution in particular has been debated by economists, political scientists, and psychologists and is an area of active research in these fields. Some empirical studies argue that such attitudes in adulthood are largely shaped by a person's immutable characteristics, such as genetic traits or country of origin, whereas other studies find a significant role for exposure to important events, especially if these are experienced during a person's formative years. ${ }^{5}$ By reporting evidence that individuals directly harmed by the pandemic are more likely to favor redistributive policies, our study provides further evidence that personal experiences have significant effects on attitudes toward public policies, although it is too early to determine how long-lasting such effects will be.

In this regard, our results are consistent with the findings of studies that analyzed the impact of economic recessions on attitudes toward public policies. Tracking the labor market experiences and political attitudes of a sample of US individuals over

\footnotetext{
5 Some studies argue that genetic traits explain between one-third and one half of the variability among people on their political attitudes (Alford et al., 2005, 2008). Genes related to sensitivity to threats seem to be correlated with conservatism, whereas those related to openness to experience seem to be correlated with liberal/progressive views (Hatemi et al., 2011, Jost et al., 2003; see Haidt, 2012 for a review). Researchers have also found that immigrants' preferences regarding redistribution are correlated with the average preference in their birth countries, and the effects persist into the second generation (Luttmer \& Singhal, 2011). Other studies report evidence that important events, especially those with large economic impact, have long-lasting effects on attitudes toward public policies and preferences for redistribution. Such events include economic recessions (as noted in the main text) or personal windfall gains. For example, a study of the formation of beliefs in a squatter settlement in the outskirts of Buenos Aires exploited a natural experiment that induced an allocation of property rights that is exogenous to the characteristics of the squatters. It found that lucky squatters who ended up with legal land titles reported beliefs closer to those that favor the workings of a free market, including a belief that one can be successful without the support of a large group (Di Tella et al., 2007).
} 
2007-2011, Margalit (2013) found that people who lost their jobs became more favorable toward welfare spending, and that this effect was larger among Republicans than among Democrats, although the effect dissipated as individuals regained employment. ${ }^{6}$ In a similar vein, people belonging to a cohort that experienced a recession when young have been found to believe that success in life depends more on luck than effort, to support more government redistribution, and to be prone to vote for left-wing parties (Giuliano \& Spilimbergo, 2014). ${ }^{7}$ Moreover, members of a cohort aged 18-25 during an epidemic in a given country are less likely to trust their government, even years after the epidemic has ended; such adverse effect is stronger in democracies and in countries where the incumbent government has weak implementation capacity (Aksoy et al., 2020).

\section{Recent survey-based studies on morality and fiscal policy preferences}

Before turning to the design of our survey and its results, it is helpful to summarize a few findings from studies that used surveys to elicit people's views on morality and fiscal policy choices. Spurred by advances in moral psychology (e.g., Haidt, 2012), economists have recently started exploring the relationship between people's moral views and their preferences for policies, including fiscal policies. Enke et al. (2020) show that the traditional left-right divide-with the left favoring more foreign aid, affirmative action, environmental protection, welfare, and universal health, and the right supporting spending on the military, police and law enforcement, and border controls-is common across several Western countries and ultimately explained by whether individuals' moral values are primarily universalist or communitarian. They define universalist moral values as altruism or trust in others that is unaffected by social distance in terms of links by family, nationality, religion, and so on. Conversely, communitarian moral values are those where altruism and trust in others decline with social distance. ${ }^{8}$ Enke (2020) shows that the universalist versus

\footnotetext{
6 A strength of Margalit's (2013) paper is that, like the present one, the survey responses include an individual's personal experience (job loss in his paper; COVID-19-related job loss or severe illness in ours). Our finding that personal experience with the pandemic shapes people's views on taxation, and progressive taxation in particular, is perhaps even more revealing than results relating to people's preferences for welfare programs. People who lose their job have a direct interest in an expansion in welfare programs (such as unemployment benefits). Instead, for a newly unemployed person, the direct benefits of progressive taxation are less straightforward and may therefore reflect a more profound change in an individual's views regarding policies that affect society as a whole.

7 In our work, we place less emphasis on the hypothesis that experiencing adversity in one's formative years affects one's preferences, because COVID-19 is less harmful, on average, for the health of the young. As shown below, interacting age with other variables of interest does not yield significant results in our estimates.

${ }^{8}$ In recent years, a growing number of empirical studies have estimated the extent to which a given population is more altruistic vis-à-vis its own members than newcomers. For example, Dahlberg et al. (2012) exploit exogenous variation in immigrant shares stemming from a nationwide program placing refugees in municipalities throughout Sweden during 1985-1994 and match data on refugee placement to panel survey data on inhabitants of the receiving municipalities; they find significant, negative effects of increased immigration on the support for redistribution.
} 
communitarian distinction is predictive of voting behavior and in-group favoritism in donations and volunteering.

These results allow us to elicit respondents' moral perspectives without "priming" them through questions about party affiliation. We ask respondents about their preferences regarding certain expenditure categories both because this is of intrinsic interest and because it gives us information about their moral values. Specifically, we ask respondents whether they would prefer to increase or decrease spending on the police, the military, border protection, health, education, and social spendingas in Enke et al. (2020). Based on individuals' responses regarding which types of spending they favor, we classify them as universalist or communitarian. In addition, we ask separate questions about "climate change" and "the local environment," in an attempt to tease out the difference between the universal and local components of environmental issues, as well as a question about infrastructure, which in principle could appeal to both universalists and communitarians.

\section{Data and descriptive statistics}

\subsection{Data sources}

The main data source is a survey (provided in full in Annex I) that was run during October 9-23, 2020, with the support of Dynata (a commercial survey company), which has email lists of respondents to whom it sends survey links for completion over a website. The sample covered 2519 US resident adults. Standard census quotas were used to ensure a representative sample by gender, age, region, and ethnicity.

The survey begins with questions to collect data on the respondents' gender, age, household income, and home ZIP code. It then provides a paragraph (see Appendix) that motivates the subsequent questions by noting the fiscal costs of the pandemic and the potential need for fiscal reforms after the pandemic ends. This is followed by the survey's main questions covering attitudes toward temporary levies and structural progressive tax reforms following the COVID-19 pandemic. Then, the survey turns to questions regarding attitudes toward public spending and other aspects of public policies. The survey concludes by returning to factual questions about personal experiences with COVID-19 and further background on education, ethnicity, and household size.

All respondents received the same questions. However, in the first two questions, which refer to a temporary levy to be implemented after the pandemic, such levy was described by one of six terms (Tax, Solidarity Tax, COVID-19 Recovery Tax, Contribution, Solidarity Contribution, COVID-19 Recovery Contribution), randomly allocated to 420 questionnaires each (419 for "Tax"). The goal of this variation was to compare how people respond to different labels ("tax" versus "contribution"), appeals to different values/goals ("solidarity" versus "recovery"), and explicit reference to the COVID-19 pandemic as the source of the shock requiring a fiscal policy response. The question was phrased in a way that makes it clear that, regardless of label, payments would be mandatory, and their size would be outside the control of the contributors. 
To explore the role of location (in particular, urban versus rural), the data were combined with the 2013 urban influence code published by US Department of Agriculture. As these codes are available by state county, they were matched to ZIP codes using a bridge file published by the Missouri Census Data Center. ${ }^{9}$ In some robustness tests, instead of self-reported personal experience from the survey answers, we use data on COVID-19-confirmed cases and deaths as share of a county's population, as of the day before the start of the survey, from USAFACTS. ${ }^{10}$ As these are also reported on a state-county basis, we match them to the survey data using the same bridging procedure.

By the time the survey was conducted, the pandemic and its economic impact were perhaps the most significant development both globally and in the USA since World War II. As of early October 2020, the cumulative number of deaths from COVID-19 in the USA was around 200,000 and the cumulative number of confirmed cases was just over 8 million. The unemployment rate at end-September was 6.9 percent, compared with the monthly peak of 14.8 percent in April 2020. The two main political parties in the USA were sharply divided regarding appropriate policies to stem the health and economic impact of the disease. The public's perceptions of the severity of the pandemic also differed significantly, depending on party affiliation.

The timing of the survey coincides with a highly polarized electorate a few weeks prior to an election. From an analytical perspective, the advantage of survey results collected as late as October 2020 is that by this time a sizable proportion of the US population had already had direct, personal experience of the devastating health and economic impact of COVID-19. The pandemic was perhaps the most salient issue in public discourse at least since March 2020, and the US electorate had been unusually polarized for years. In our view, conducting the survey earlier in the year would have been less informative from the perspective of personal experience with COVID-19 and would have been just as influenced by respondents' political leanings (and their underlying moral perspectives, which we fully wanted to capture).

A further potential concern-common to recent online surveys in the USA, such as the one used in this paper-is a growing difficulty, particularly since 2016, in ensuring adequate participation by older respondents with lower educational attainment who lean Republican and have little trust in government, data, or experts. Existing estimates of the possible resulting bias find that it is limited, especially where there are significant efforts to obtain a representative sample (Kennedy et al., 2021); moreover, as we explain below, our interest is primarily in estimating interaction terms rather than seeking to identify a majority view.

\footnotetext{
${ }^{9}$ See US Department of Agriculture, "Urban Influence Codes" (https://www.ers.usda.gov/data-products/ urban-influence-codes/), and Missouri Census Data Center, "Metadata for dataset zcta_master," (http:// mcdc.missouri.edu/data/georef/zcta_master.Metadata.html). This allowed matching an urbanity code to all but 38 observations, whose ZIP code does not appear in the bridging file.

${ }^{10}$ These data are available at a daily frequency. See USA Facts, "US COVID-19 Cases and Deaths by State" (https://usafacts.org/visualizations/coronavirus-covid-19-spread-map/).
} 


\subsection{Sample characteristics}

The quantitative demographic variables in the sample (Table 1) are close to US aggregate statistics. The median age is 43 years, slightly above the US median of 38.5. The average household size is 2.7 , marginally above the US average of 2.6. ${ }^{11}$

Inspection of the responses does not raise concerns about contradictions or obvious inaccuracies beyond a few limited cases. Analysis of frequency plots and extreme values reveals that a few respondents likely did not accurately disclose their age, perhaps to protect their privacy. Twenty respondents claim to be 99 years old (the maximum option allowed in the survey), but their other answers seem otherwise reasonable. The pattern at lower ages is plausible, with declining numbers of respondents in their 60s (332), 70s (139), 80s (22), and 90s other than 99 (6). For the number of own children, no such effect occurs. As the number of reported own children rises, there are steadily fewer respondents. Only four people report having the maximum permissible figure of 9 children. Regarding household sizes, the maxima of 19 people are high but rarely reported (one household reporting 19 children, three households reporting 19 adults). All report 1-3 adults in the household, with one exception (19 adults in the household). Overall, these descriptive statistics appear broadly reasonable and representative.

The categorical data (Fig. 1) reveal that the sample is diverse, covering all regions, ethnicities, genders, levels of education, and income. The sample is slightly more urbanized than US aggregates ${ }^{12}: 59$ percent ( 55 percent USA) live in large metropolitan areas (more than 1 million inhabitants). Another 29 percent (30 percent USA) live in small metropolitan areas (areas with an urbanized center of at least 50,000 people). Seven percent (8.8 percent USA) live in micropolitan areas (areas with an urbanized center of at least 10,000 inhabitants). The remaining 5 percent (6.2 percent USA) live in noncore areas (that is counties without a metro- or micropolitan core).

Respondents in the sample are more highly educated than the US average population ${ }^{13}$ : 93 percent have completed high school (88 percent USA), 57 percent have completed college (42 percent USA), and 21 percent graduate school (12 percent USA). Household incomes are, however, lower than for the US average population ${ }^{14}$ : 23 percent report household income up to $\$ 20,000$ (13 percent USA) and 51 percent have incomes up to $\$ 50,000$ (37 percent USA). Only 9 percent report incomes above $\$ 150,000$ (19 percent USA); 20 percent have incomes above $\$ 100,000$ (34 percent USA). The lower income in combination with higher education is somewhat surprising. Potential explanations are that respondents might know their own income but not

\footnotetext{
$\overline{11}$ The US aggregate figures are from US Census Bureau, 2019 American Community Survey 1-year Estimates.

${ }^{12}$ US aggregate figures from US Department of Agriculture, "Urban Influence Codes-Documentation" (https://www.ers.usda.gov/data-products/urban-influence-codes/documentation/).

13 The US averages are taken from US Census Bureau, 2016, "Educational Attainment in the United States: 2015."

${ }^{14}$ US averages from US Census Bureau, Current Population Survey, 2020 Annual Social and Economic Supplement (CPS ASEC).
} 


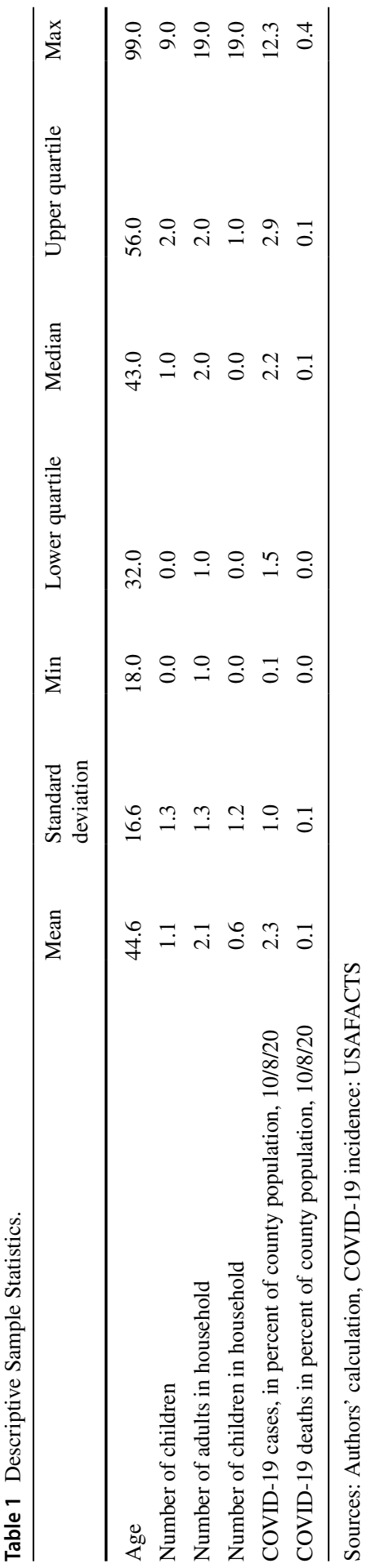



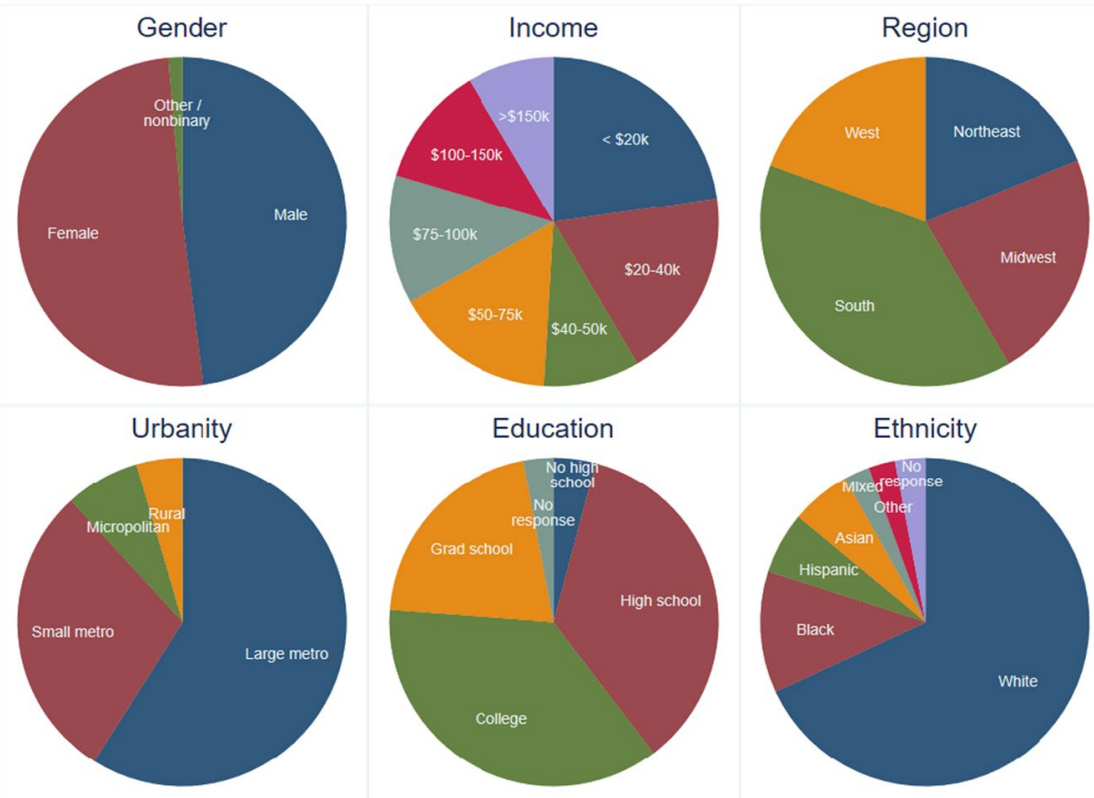

Fig. 1 Description of Sample Source: Authors' calculation, Urbanity: US Department of Agriculture

necessarily the household's, they might not correctly gross up the taxes, and for those affected by the pandemic, recent income losses may be reflected, even though the question was about the preceding year.

Although the sample is diverse and broadly reflective of the general US population, we would not consider it appropriate to focus on whether a majority of respondents is in favor of or against a specific policy proposal. It might be the case, for example, that people with, say, conservative attitudes, are reluctant to participate in surveys. Indeed, our finding reported below of a larger share of universalists than communitarians could stem from underrepresentation of that group. However, we do think that the survey yields informative results concerning the correlations between preferences and various factors, interactions among various factors, or the relative appeal of various types of policies within a broad category. What would matter for our study is differential nonresponse by, say, communitarians, based on their personal experience with COVID-19, which we consider unlikely given the robustness tests shown below, but cannot fully rule out. 


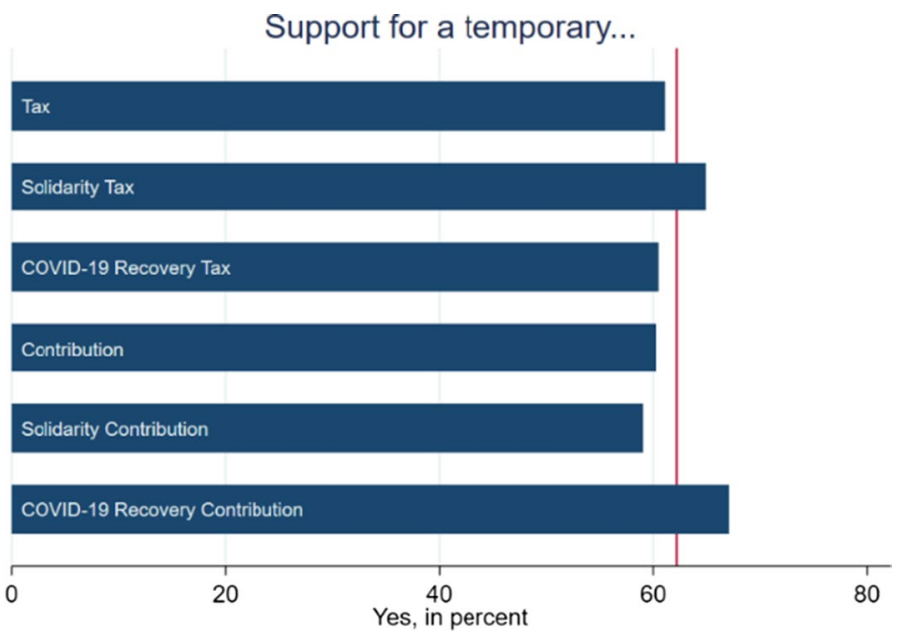

Fig. 2 Responses to Question 1. These are responses to the question: "Would you support the introduction of a temporary [tax/solidarity tax/COVID-19 recovery tax/contribution/solidarity contribution/ COVID-19 recovery contribution] charged on those who are well off, to cover the costs of fighting the COVID-19 pandemic and its economic impact?" with each respondent being assigned randomly one of the six terms. Respondents could answer "yes" or "no." The red line shows the average across all terms. Source: Authors' calculation

\section{Survey results}

\subsection{Questions on tax reform}

The first question is about a temporary post-pandemic levy, described using a term varying across respondents (allocated to one of six groups through random selection within the sample, for this purpose):

Question 1: Would you support the introduction of a temporary [tax/solidarity tax/COVID-19 recovery tax/contribution/solidarity contribution/COVID-19 recovery contribution] charged on those who are well off, to cover the costs of fighting the COVID-19 pandemic and its economic impact?

Considering all definitions of the levy jointly, 62 percent of respondents in the sample are supportive of a temporary levy to cover the costs of the pandemic, with little variation across the different terms (Fig. 2). The term gaining the highest approval rating is "COVID-19 Recovery Contribution" at 67 percent. This is the only term significantly different from the average (with $p$-value of 2 percent). ${ }^{15}$ Explaining the factors underlying the yes/no answers to this question is a key purpose of this paper.

Question 2: Assuming such a temporary [tax/solidarity tax/COVID-19 recovery tax/contribution/solidarity contribution/COVID-19 recovery contribution] were introduced, which of the following would you support?

$\overline{15}$ This result holds if the control variables of the subsequent regressions are included. 


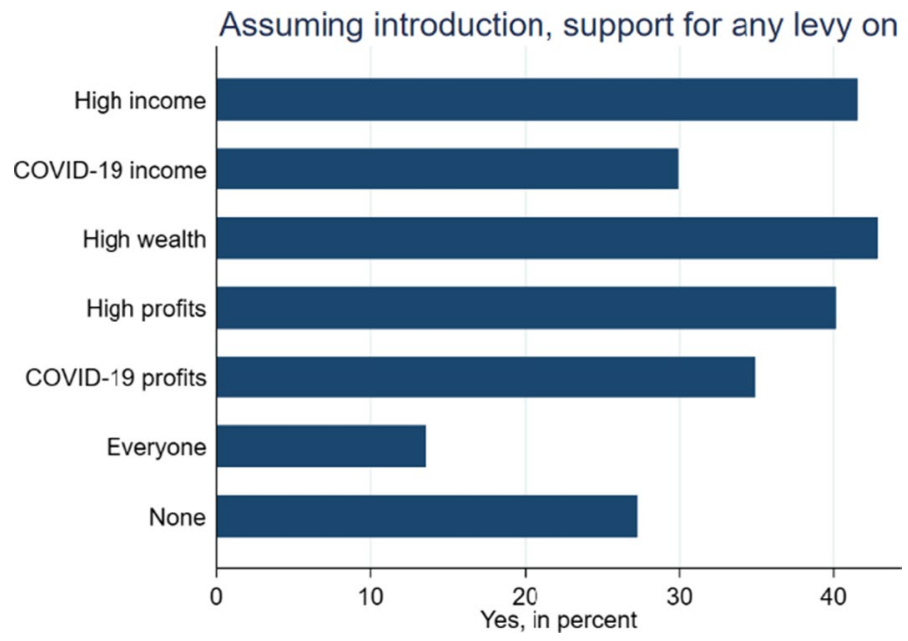

Fig. 3 Responses to Question 2. Notes: These are responses to the question: "Assuming such a temporary [tax/solidarity tax/COVID-19 recovery tax/contribution/solidarity contribution/COVID-19 recovery contribution] were introduced, which of the following would you support?" Respondents could choose either any number of the listed tax bases or "none." Source: Authors' calculation

The second question asks about the preferred tax base for a temporary levy, allowing respondents to select all options with which they agreed (only the final option of "none" was not allowed to be combined with any of the preceding ones).

The results confirmed that, among respondents who accepted the premise of a temporary levy being introduced (one quarter of respondents rejected the premise), the vast majority preferred a progressive tax base to a proportional tax on everyone (Fig. 3). The results reveal little differentiation between high incomes, wealth, or profits. Respondents supported more often taxes on incomes or profits that are high regardless of the underlying causes, rather than resulting specifically from the pandemic.

Question 3: Would you support a permanent increase in taxes raised only on those who are well off?

The third question shifted from a temporary tax to a permanent progressive tax increase, allowing respondents to state whether they would support it, for different possible uses of revenues (allowing multiple selections, again with the exception of the final option).

Support for such permanent progressive tax increase is slightly higher than for a temporary levy, with 68 percent of respondents supporting some such tax. Support differs significantly depending on its intended use (Fig. 4). The highest support was found for revenues being used for social spending (possibly influenced by previous questions), but a third of respondents supported infrastructure, education, local environment, debt reduction. Support for climate change mitigation was lower at around 25 percent. Interestingly, local spending received relatively low support. 


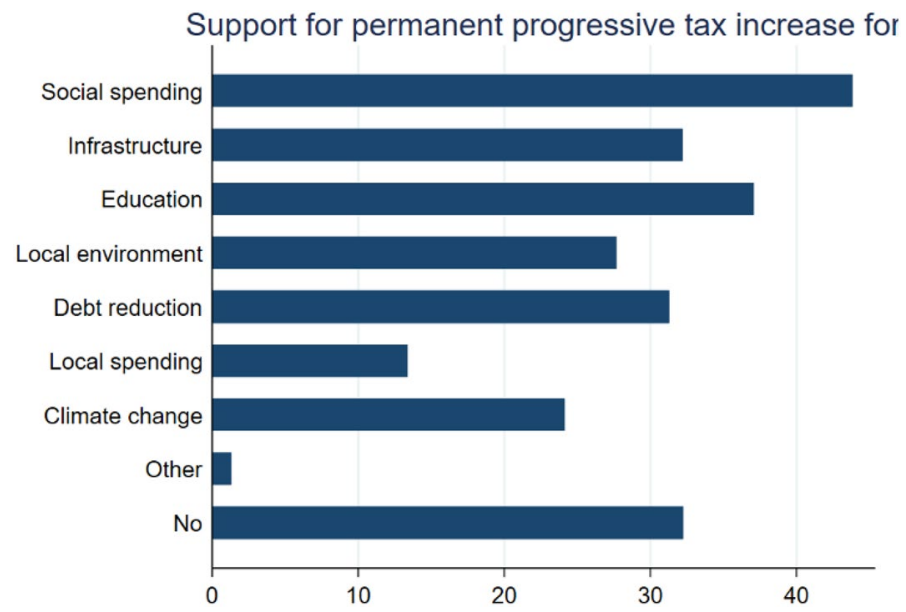

Fig. 4 Responses to Question 3. These are responses to the question: "Would you support a permanent increase in taxes raised only on those who are well off?" Respondents could answer "yes" and indicate any number of the supported uses of the funds or "no." Source: Authors' calculation

Question 4: Would you support a tax law change that raises taxes on the rich, reducing them for everybody else so that the government receives the same total revenue?

The fourth question turns to support for a revenue-neutral tax reform. At 72 percent, the level of support was slightly higher than for tax increases used for spending, whether related to the pandemic or other goals. Respondents favored options that raise taxes for the top decile or top percentile (Fig. 5), presumably because few respondents considered themselves part of those groups.

Support for tax increases on the top decile was marginally stronger than on the top percentile. Given that respondents could select as many options as they wished, one expected pattern would have been steadily declining support as the income level for being included in the new tax falls. The strong preference of a tax on the top decile rejects that pattern. The preference for a tax on the top decile could reflect a concern that a tax on the top percentile only would raise little revenue and thereby limit the beneficial impact on those with lower incomes. Alternatively, it could reflect some sense of fairness requiring that all rich individuals contribute. Some respondents may simply have overlooked or misunderstood the information telling them that they should choose all statements that applied. Out of 963 people who supported a tax on the top decile, 420 people did not select any of the other options.

\subsection{Background questions}

\section{Question 5: Which of the following statements do you agree with?}

The first part of this question asks respondents about their views on the general tax level, allowing them to choose one of three options. In total, 56 percent considered taxes to be too high, 33 percent considered them about right, and the remaining 11 percent considered them too low. The generally high support for tax increases 


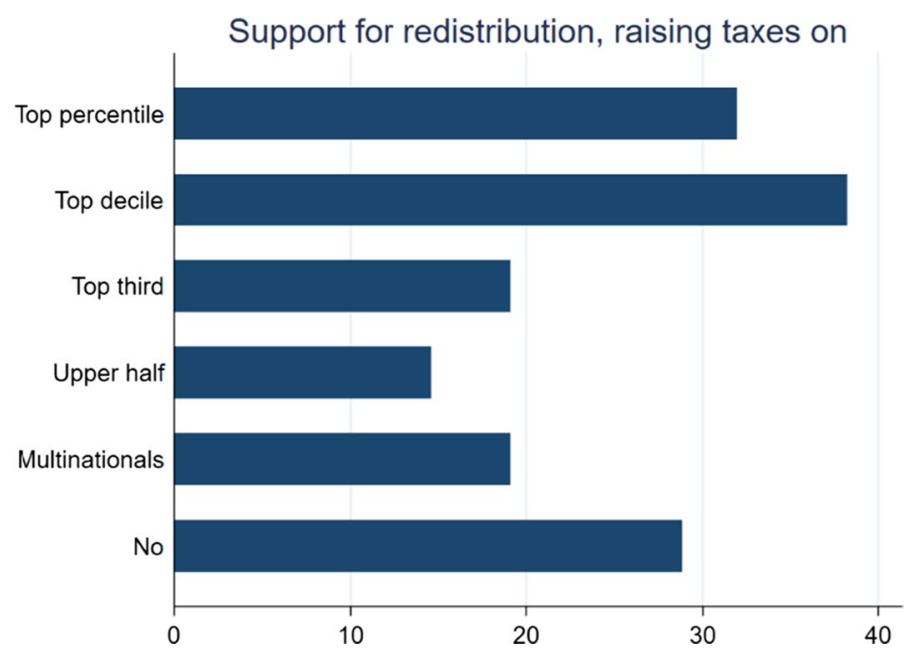

Fig. 5 Responses to Question 4. These are responses to the question: "Would you support a tax law change that raises taxes on the rich, reducing them for everybody else so that the government receives the same total revenue?" Respondents could answer "yes" and indicate any number of the groups for whom taxes would be increased "no." Source: Authors' calculation

revealed in the previous questions contrasts with the widespread perception that taxes are already too high. Support for tax increases may thus be conditional on their progressive nature, whereby only the richest taxpayers would be affected.

The second part of the question allows respondents to choose as many statements as they wish from a list summarized in Fig. 6. The majority of respondents believe that the rich do not pay their fair share in taxes. This provides a plausible explanation of why respondents hold the view that taxes were already too high, but that additional taxes on high incomes or wealth would be justified. The national debt worries 40 percent of respondents. A minority of respondents think that taxes are generally squandered or that excessively generous benefits lead to complacency among poor people.

Question 6: Would you favor more or less government spending for the following (At least one needs to be "less")?

To elicit individual respondents' moral attitudes, we asked about their preferences regarding different public spending items. By imposing upfront that at least one category had to be cut, the question enforced some minimal form of budget constraint on respondents. Among respondents to our survey, views were on average more favorable for health, education, and infrastructure spending, whereas the areas with the largest shares of responses favoring cuts were border protection, the military, and the police (Fig. 7).

Question 7: Who has, in your opinion, suffered the most during the pandemic?

This question allowed respondents to choose all applicable options. Almost half of respondents identified poor people as those who suffered the most (Fig. 8). The second most frequent choice was old people, likely reflecting concerns about health. 


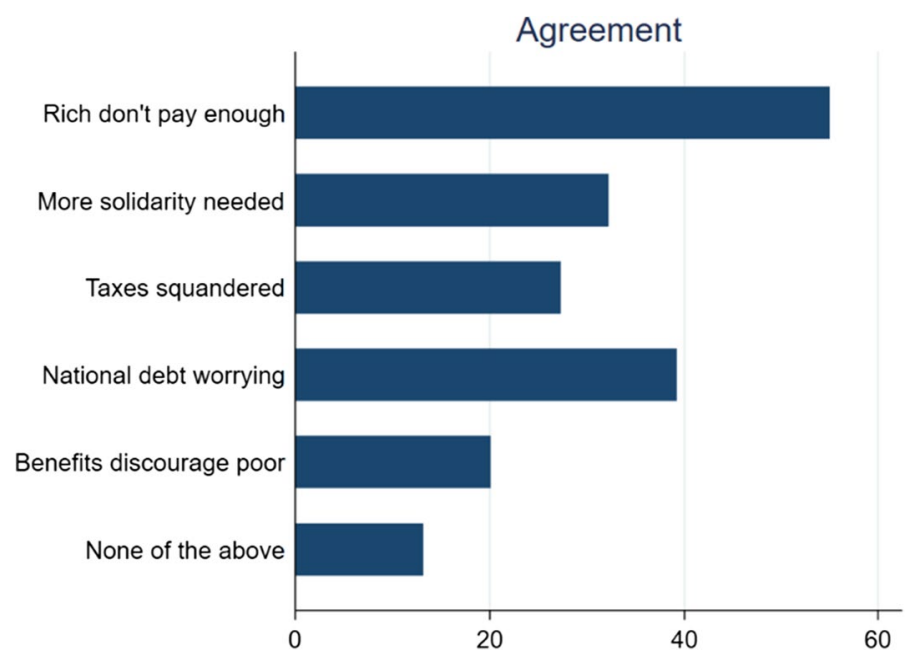

Fig. 6 Responses to Question 5. These are responses to the question: "Which of the following statements would you agree with?" Respondents could choose either any number of the statements or "none of the above." Source: Authors' calculation

Only ten percent identified women as having suffered most, despite some evidence that they have borne more of the cost.

As no restrictions were imposed on the combination of chosen answers, some interesting combinations occur. For example, out of the 800 people (32 percent of the sample) who selected the statement that everyone had suffered about equally, 274 picked at least one more answer, singling out a group that suffered most, and 157 specifically also selected that poor people had suffered most. This contradiction either reflects a misunderstanding of the statement that everyone had suffered about equally or it might reflect some idea that equally adverse outcomes would be felt more strongly by the poor. In total, 54 respondents selected both the statement that the poor and the rich had suffered most, reflecting either a mistake or a belief that the middle class fared better. Totally, 215 people thought that young people and old people had suffered the most, perhaps reflecting a view that middle-aged people have been comparatively sheltered. A few (9) respondents picked all answers, suggesting they overlooked the term "most" in the question.

Question 8: How has the COVID-19 pandemic directly affected your life?

This question turns to the personal experiences with the pandemic, allowing respondents to choose all applicable statements listed in Fig. 9. In total, 45 percent reported no direct impact on their household. More than 20 percent reported employment loss in their household, and 9 percent reported serious COVID-19 illness in their household. The latter seems high compared to the official figures on COVID-19 cases as a share of the population, which averages 2.3 percent in the sample (average of county-level ratios over all respondents for which such data could be matched based on ZIP codes, as of the day prior to the survey). Potential explanations include that respondents may have interpreted the term "household" in a broad sense (and of course, one case in the household is sufficient) and that respondents who had experienced symptoms reported 


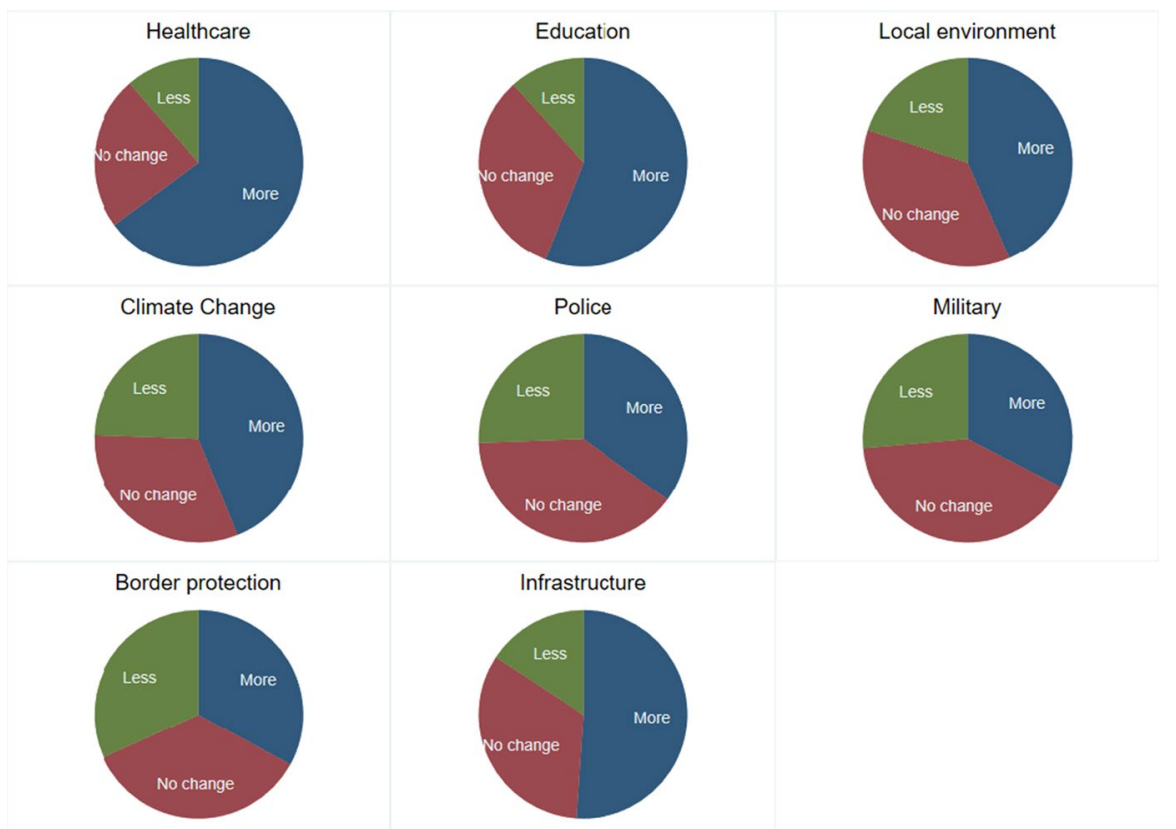

Fig. 7 Spending Preferences. These are responses to the question: "Would you favor more or less government spending for the following (At least one needs to be "less")?" Source: Authors' calculation

them as COVID-19 even in the absence of a positive test result. Eighteen percent report that someone they know became seriously ill with COVID-19.

As in the previous questions, some combinations of responses are puzzling. Out of the 1138 respondents claiming that their household had not been directly affected by the pandemic, 25 reported employment loss, 24 reported critical COVID-19 illness in their household, and 13 reported both. Comparing the puzzling answers across questions reveals that out of the 36 respondents who claimed no direct impact of the crisis, while facing employment loss or critical illness, 9 also picked the option that everyone had suffered equally from the pandemic, while singling out at least one category as having suffered most (but only 2 of them picked all options under Question 7). None of the respondents providing these puzzling answers claimed to be 99 years of age.

Overall, the number of obviously questionable answers is thus quite low and given that puzzling answers in one response are not accompanied by overall nonsensical answers, they do not appear to reflect a generally noncooperative attitude 


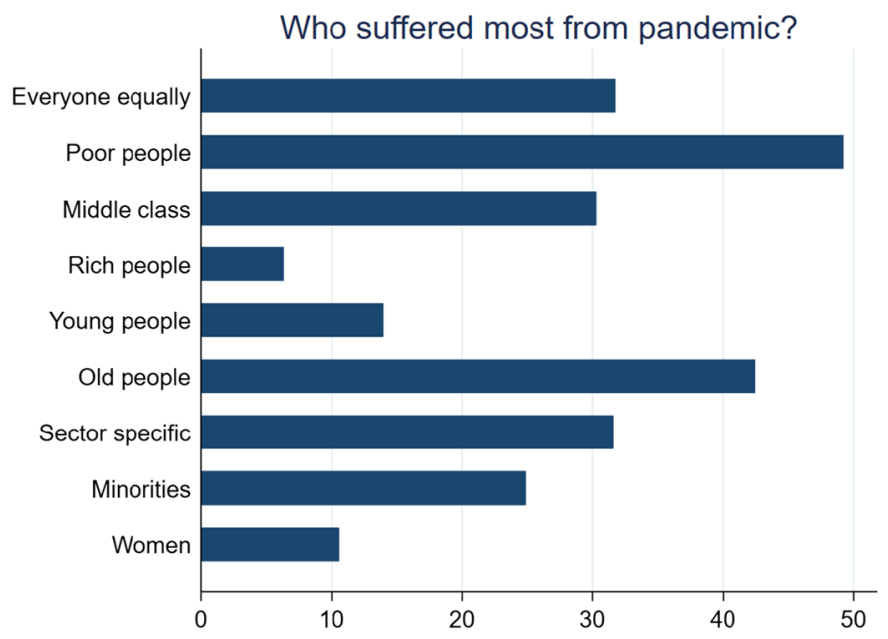

Fig. 8 Responses to Question 7. These are responses to the question: "Who has, in your opinion, suffered the most during the pandemic?" Source: Authors' calculation

by their respondents. Even so, we repeated all of the following analyses also having excluded the 55 respondents claiming to be 99 years of age or providing contradictory answers to Question 8, and this did not affect the results significantly.

\section{Regression analysis}

In this section, we use logit regression analysis to examine the choices of respondents controlling for various factors simultaneously (Table 2). ${ }^{16}$

Regression (1) shows that direct suffering from the pandemic is associated with significantly higher support for a levy, with a marginal effect of 11 percentage points. Among the control variables, the likelihood of support rises with household size, having children, ${ }^{17}$ the level of education, and being of black/African-American ethnicity. The respondents' gender has no significant impact. Support declines with being above median age (of 43 years) and drops strongly for respondents who refuse to indicate their ethnicity. A potential interpretation might be that those who do not report their own ethnicity may be opposed to policies favoring better distribution of incomes and opportunities. The relationship with income is hump-shaped: Earning more than $\$ 20,000$ raises the likelihood of support, but further increases change little, and at incomes above $\$ 150,000$ support is less likely.

\footnotetext{
16 The results are extremely similar using probit, and criteria such as the Akaike information criterion do not point strongly in favor of logit or probit. Linear probability models also yield very similar results.

17 "Household size" and "having children" are similar, but not identical. Adult relatives might live in the household, and children (for example adults) might not live in the household. Having children measures links to the following generation. Household size has a higher correlation with income.
} 


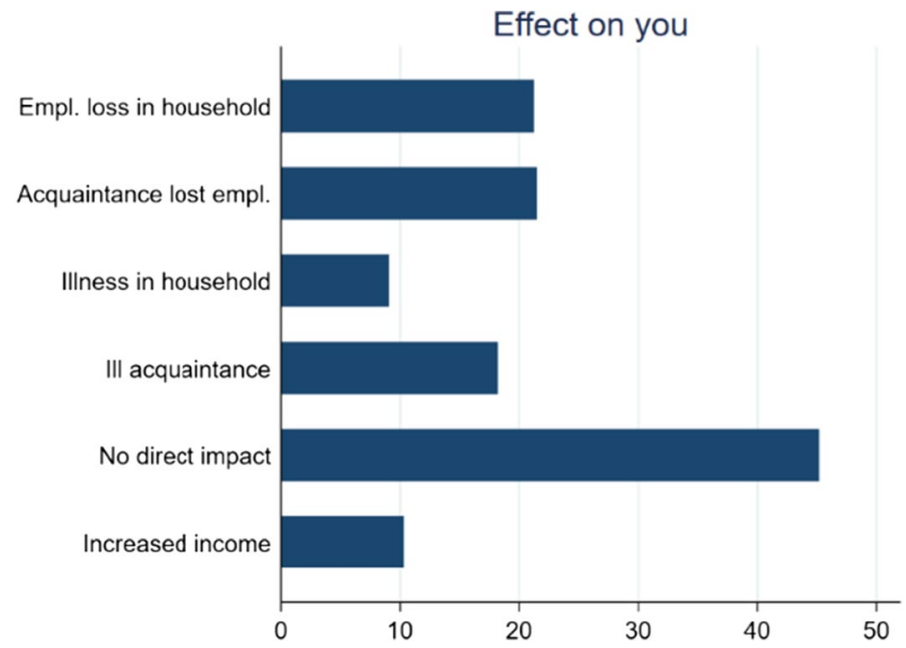

Fig. 9 Responses to Question 8. These are responses to the question: "How has the COVID-19 pandemic directly affected your life?" Source: Authors' calculation

The dummy for having suffered as well as many of these control variables (age, ethnicity, education, and income) allow further breakdowns or details, which are reported in an Online Appendix (Table A1), along with results adding a control for urban ZIP codes. Many of the additional breakdowns/variables are insignificant, but one particularly noteworthy finding of such further breakdowns is that illness had greater impact than employment loss on support for a temporary levy. Moreover, going beyond the dummy, there is a significant increase in support even for just knowing someone who lost employment or fell ill.

\subsection{Role of moral perspectives}

The next few regressions add moral perspectives of the respondents as estimated from their replies to questions about spending priorities. (As noted above, the question made it compulsory to identify at least one area for budget cuts, thus imposing some degree of budget constraint on the respondent.) Building on work by Enke et al. (2020), we assigned the following labels:

- Universalist: a respondent who (i) supported at least one of higher health, education, or climate spending, and (ii) did not ask for cuts in any of these three areas, and (iii) wanted to reduce at least one of police, military, or border protection spending.

- Communitarian: a respondent who (i) supported at least one of higher police, military, or border protection spending, (ii) did not ask for cuts in any of these three areas, and (iii) wanted to reduce at least one of health, education, or climate spending.

- Moderate: anyone who does not meet the conditions for the other two labels. 


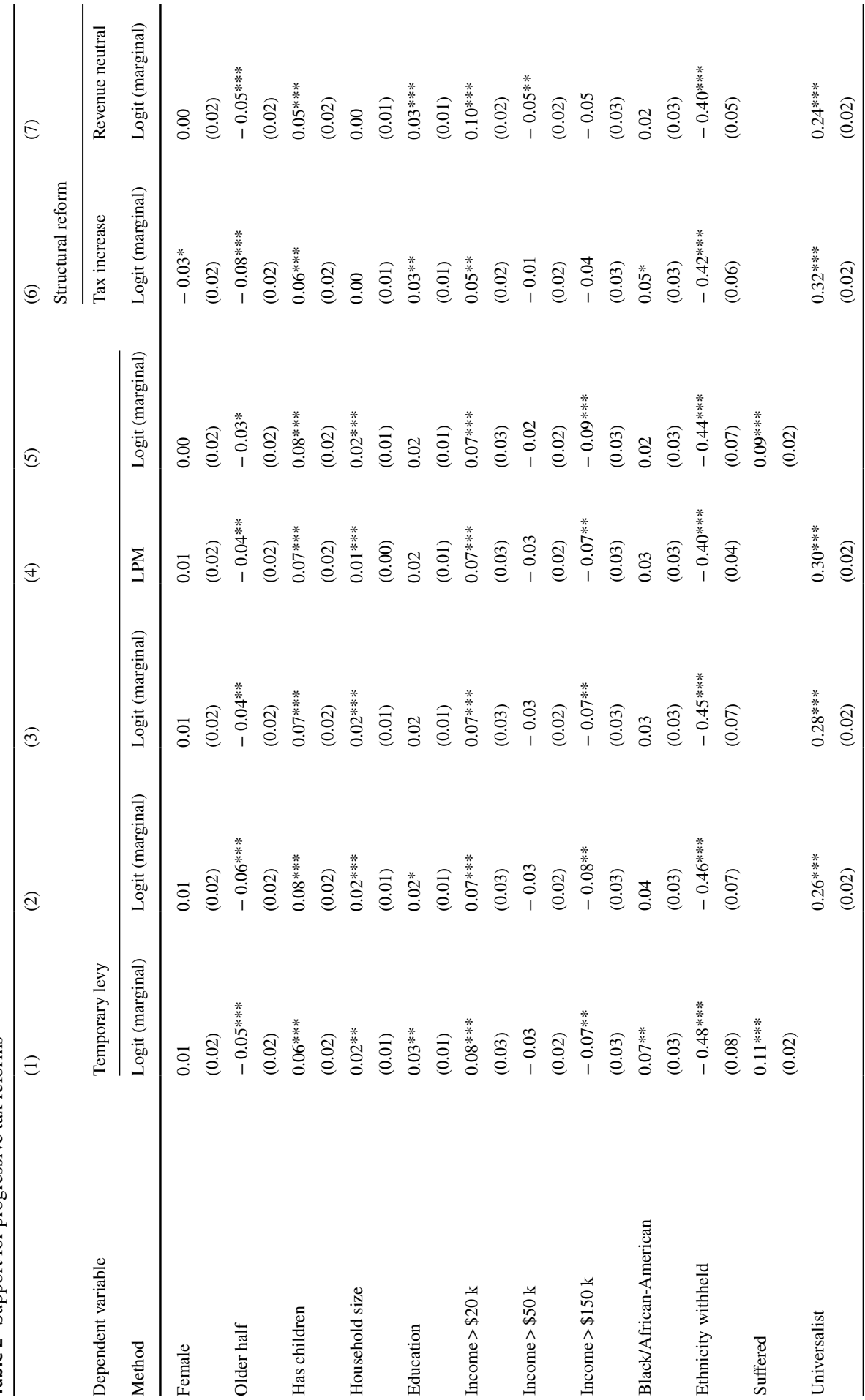




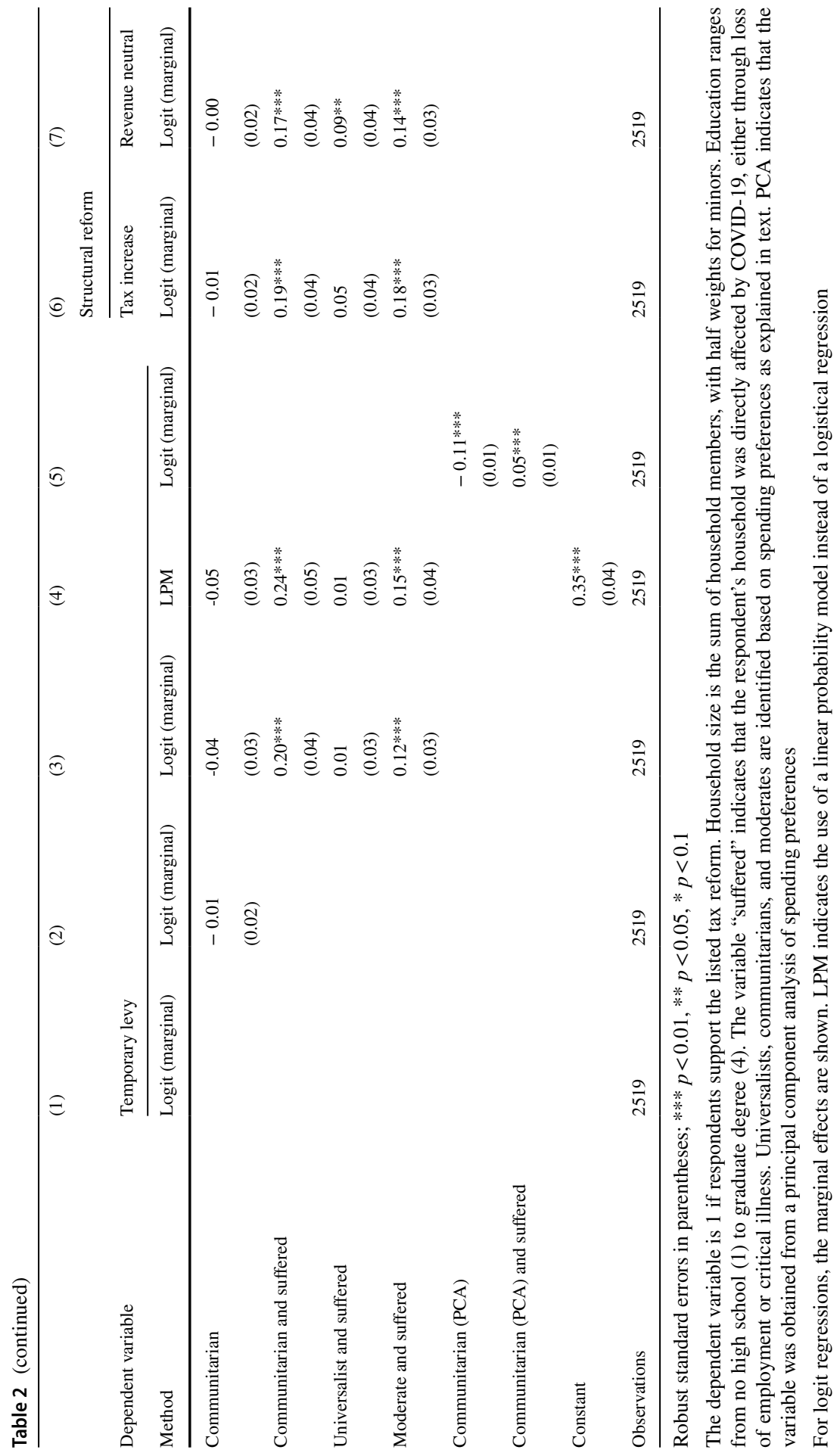


This definition yields a share of universalists of almost 50 percent and 21 percent communitarians. $^{18}$

Regression (2) shows that universalists, identified based on spending preferences, are significantly more likely to support a temporary levy—with a marginal effect of 26 percentage points. In regression (3), we interact the estimated moral perspectives with the indicator for having suffered in the household from employment loss or illness. Communitarians are generally less likely to support temporary levies, but the likelihood for support rises for those whose households have been directly affected by the pandemic, and this increase is strong with a marginal effect of 20 percentage points. Universalists are more likely to support temporary levies, but their support does not rise significantly as a result of their own households having been affected. Support also rises for moderates with a marginal effect of 12 percentage points.

In interpreting the finding of a greater shift in preferences among communitarians, it is helpful to consider that, with the higher starting level of support among universalists, there may be less room for such shift. ${ }^{19}$ To explore this potential factor, we seek to approximate the increase in share of respondents supporting a temporary levy, among those who can change their mind. To do so, we assume that the share of universalists and communitarians who pre-pandemic were not in favor of progressive taxation is the same as for the sample of people in the survey who did not personally experience illness or job loss in the household (that is, the 23 percent of unaffected universalists and the 57 percent of unaffected communitarians who do not support a temporary levy). To facilitate hypothesis testing, we rerun regression (3) in a linear probability model version, reported in regression (4). Dividing the increase in support in the affected group ( 1 percentage points among universalists and 24 percent among communitarians) by those who could potentially have changed their mind, yields that 3 percent of universalists otherwise opposed to temporary levies, support them if exposed to COVID-19, whereas the figure for communitarians is 42 percent. The increase for communitarians is thus greater than for universalists even in percent of those who could potentially change their mind. The finding of a greater change among communitarians is not simply driven by a larger pool of people initially opposed. The $p$-value for the difference in ratios is 0.6 percent.

As a robustness check, we also extracted moral preferences using an alternative method based on principal component analysis. The first principal component shows clearly that a preference for spending cuts in health, education, local environment, and climate change is aligned among respondents. Infrastructure spending cuts are of the same sign, but at a lower coefficient. Preferences for cuts in police, military, and border protection have the opposite sign. Specifically, the principal component analysis was run on the spending categories, with each variable taking values of 1

\footnotetext{
18 Online Appendix Table A2 also shows results with spending preferences entered directly as explanatory variables. Moreover, to ensure that these assignments reflect underlying moral perspectives, we regressed them on the value statements of Question 5 (Online Appendix Table A3). The results align strongly with priors about communitarians and universalists.

19 Margalit (2013) discusses a similar situation and suggests as solution focusing only on those not already in favor of the policy of interest.
} 
for preferences for more spending, 2 for unchanged spending, and 3 for cuts. The first eigenvector of the principal component analysis is: health $(0.362)$, education (0.3844), local environment $(0.4495)$, climate change $(0.4709)$, police $(-0.2648)$, military $(-0.2856)$, border protection $(-0.3411)$, and infrastructure $(0.1717)$. The first component has a variance of 2.4 explaining 30 percent of the total.

We use the first principal component as a measure of communitarian preferences. Regression (5) replaces the categorizations of moral perspectives based on spending preferences by the score from the first principal component. The results hold up, with the likelihood of supporting a temporary levy declining with communitarian preferences, while having suffered under the pandemic reduces opposition to a temporary levy.

Regression (6) reports results for a permanent progressive tax increase, while regression (7) considers a revenue-neutral redistributive reform. The pattern of results for both permanent progressive tax reforms is quite similar to temporary levies, even though such longer-term reforms are less closely related in time to the pandemic and its costs. Every progressive reform garners significantly higher support from people identified as universalists, whereas the increase in support following COVID-19 exposure is greater among communitarians.

\subsection{Perceptions about COVID-19 risks across moral perspectives}

Universalists and communitarians might have not just different preferences, but also different perceptions about the severity of risks from COVID-19 or of the resulting suffering. To analyze this possibility, we regress the responses regarding each respondent's household exposure to COVID-19 on their moral perspectives (Table 3). The results reveal that universalists are more likely to claim to have suffered economically or to have a critically ill acquaintance, but they were no more likely to report illness in their own household controlling for the incidence of COVID-19 cases and deaths in each county. When considering the variables used in the regressions ("suffered," which indicates that a household is affected and does not reflect ill or unemployed acquaintances), the difference becomes insignificant. It is also reassuring that the likelihood of reporting illness in the household or among acquaintances rises in areas with high incidence. The marginal effect in both cases is 0.02 , suggesting that each additional percentage point of official cases raises the likelihood of reporting illness by 2 percentage points. Explanations for this large effect include that households are made up of more than one person and potential (self-)diagnoses in the absence of an official test, as tests were still hard to obtain at the beginning of the pandemic.

To check that our key results are not driven by an excessive impact of moral preferences on perceptions of suffering from the crisis, we repeated the main regression with objective county data on the incidence of COVID-19 cases or deaths instead of subjective, self-reported experience of suffering (Table 4, regressions (1) and (2)). The key result - that universalists are more likely to support temporary levies, but 


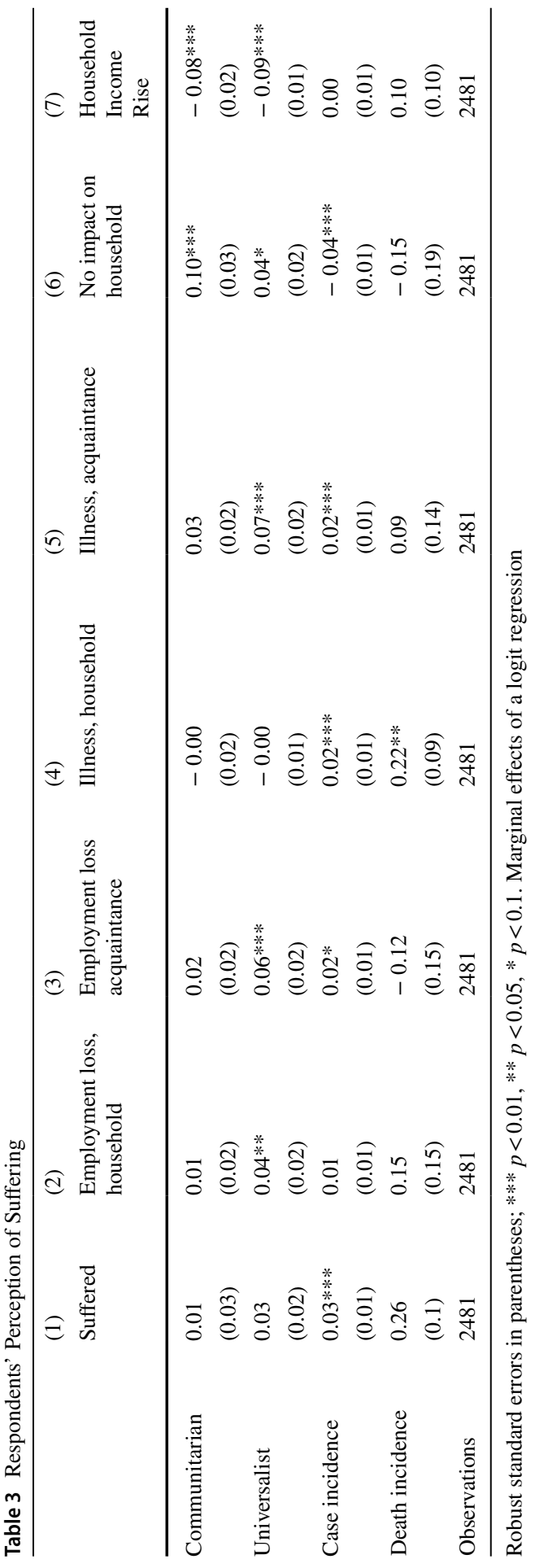




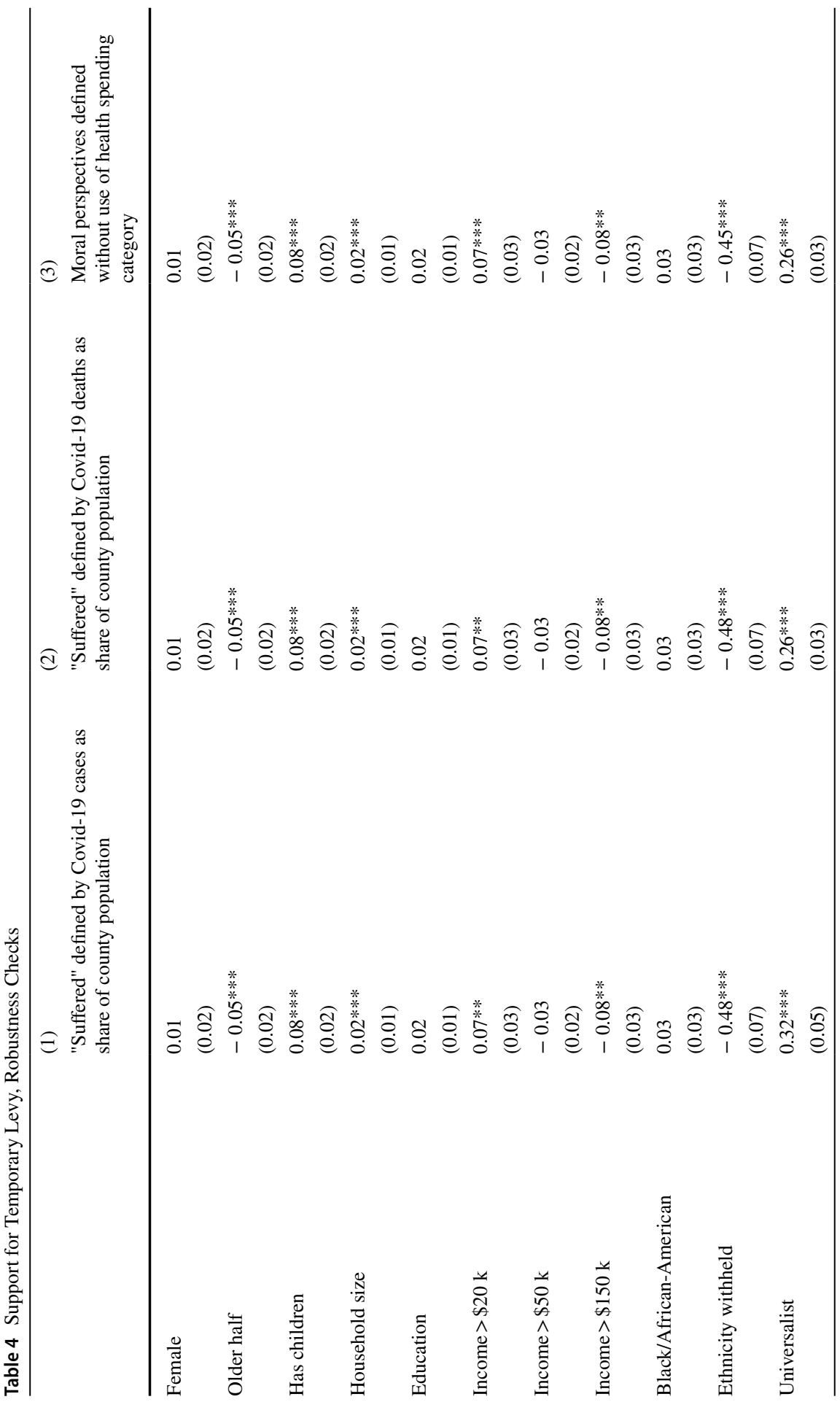




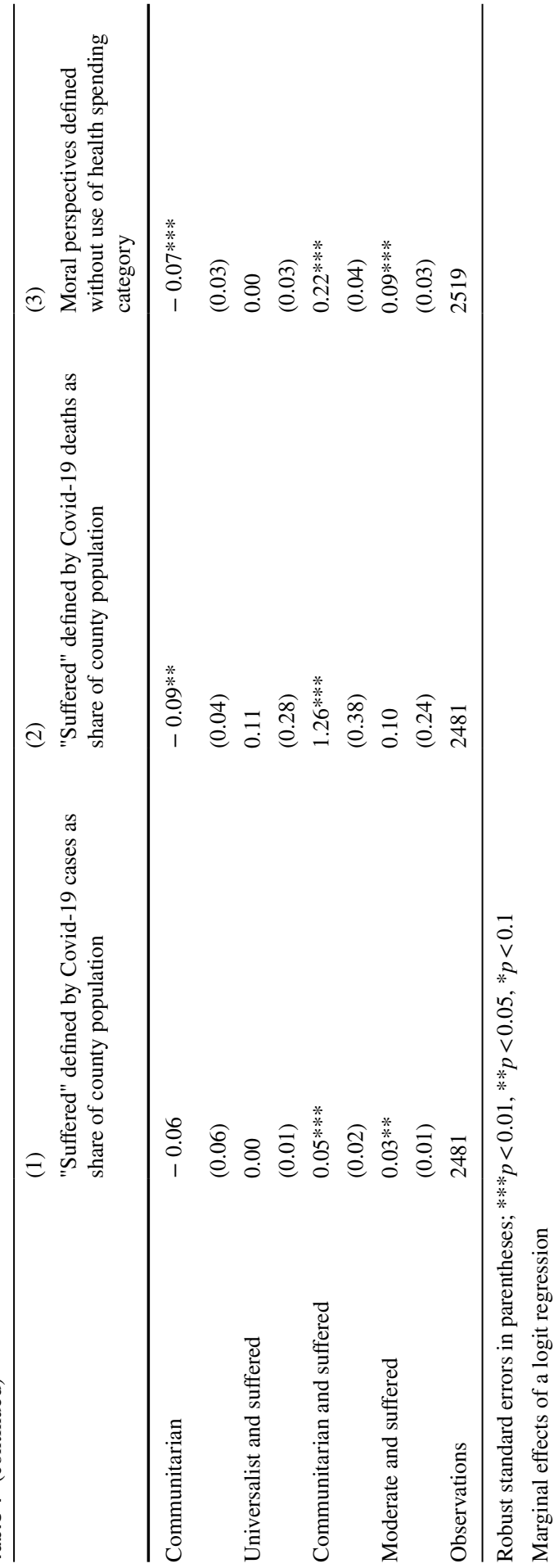


more communitarians change their view if affected by the pandemic-is confirmed, using actual data by county on the incidence of the disease. ${ }^{20}$

A similar, yet distinct, concern is that having suffered from COVID-19 might shape preferences specifically about healthcare, and hence respondents' identification as universalists or communitarians might be directly affected by their experience during crisis. ${ }^{21}$ To address this, we construct an alternative definition of universalists or communitarians that excludes spending preferences on healthcare and is otherwise identical to the one above. This does not change estimated preferences much (which is as expected, given the finding of the principal component analysis that revealed strong alignment across spending categories); the share of universalists drops slightly to 40 percent and that of communitarians to 18 percent. Estimation results hold up well (Regression (3)).

\section{Conclusion}

The evidence reported in this paper suggests that the COVID-19 crisis may have profound consequences on people's attitudes toward fiscal policy and, more specifically, taxation and its degree of progressivity. Individuals who have lost employment or suffered from the disease, or personally know someone who has, are more likely to support progressive taxation. This result is consistent with previous findings that attitudes can be molded by personal experiences during crises and other upheavals with major economic impact.

Four caveats are in order, however, and suggest directions for further research. First, in interpreting the results, it is important to consider that the pandemic is an analytically informative but also unique event, and that the timing of the survey coincides with a highly polarized electorate a few weeks prior to an election. From an analytical perspective, conducting the survey as late as October 2020

\footnotetext{
${ }^{20}$ While the spending-based estimates of moral perspectives have the advantage of avoiding a direct link to tax preferences and hence circularity, it is also interesting to assess the effects of suffering during the pandemic for people who explicitly note their skepticism about the merits of taxation (respondents who agree with the claim that "most tax revenues are squandered anyway"). Adding this to the regression shows that supporters of that claim are unsurprisingly less likely to favor a temporary levy (with a marginal effect of -7 percentage points). If their household is affected by the crisis, support rises more strongly (an additional marginal effect of 9 percentage points, that is 21 percentage points in total) than the general increase (marginal effect of 12 percent), thereby overcompensating for their previous opposition. Interestingly, there is an important group believing simultaneously that most taxes are squandered and that a temporary progressive levy should be implemented. Reasons could be psychological: long held general views might be harder to change than views regarding a specific policy. Alternatively, some individuals might simply like rich people to share a portion of the burden, irrespective of whether proceeds are well used.

21 Indeed, a regression of preferences for more health spending on having suffered and the usual controls reveals that support for health spending rises by 13 percentage points as a result of COVID-19 exposure. The resulting bias would work against the reported result: COVID-19 exposure would not only raise support for progressive taxes among communitarians, but potentially also lead to some of them being labeled as universalist. They would therefore not count toward the increase in support among communitarians.
} 
implies that a sizable share of respondents had direct, personal experience of the devastating health and economic impact of COVID-19. Moreover, both the salience of the pandemic and the polarization of the electorate remained very high throughout the year. Second, it is too early to tell whether the effects documented in this paper will be long lasting. Previous studies documented that the impact of job loss on attitudes toward welfare programs was short lived after the global financial crisis (Margalit, 2013), whereas the impact of recessions (Giuliano \& Spilimbergo, 2014) and epidemics (Aksoy et al., 2020) in forging attitudes of cohorts experiencing such upheavals during their "impressionable age" was found to be longer lasting. Even so, one might conjecture that the pandemic's acceleration after the survey's conclusion could have strengthened the effects. Third, further work will be necessary in other countries to explore the hypothesis that individuals directly bearing the brunt of the pandemic are likely to become more favorable to progressive taxation. Fourth, whereas our findings suggest that individuals who are directly hurt by the pandemic increase their demand for the state to support those in need, and that this effect is stronger for those who may have previously held unfavorable views on progressive taxation, our survey does not make it possible to test whether views against such policies become more entrenched among those who continue to hold them. Moreover, other factors may simultaneously be causing changes in attitudes. For example, other researchers have recently found that epidemics weaken trust in government (Aksoy et al., 2020).

The results are also consistent with empirical evidence from other, nonsurveybased studies (see IMF 2021 for a summary) showing the COVID-19 pandemic has worsened preexisting inequalities, and that it has laid bare inequalities in access to basic services, which, in turn, may cause income gaps to persist generation after generation. For the recovery to benefit all and to strengthen trust in government, action is needed to reduce gaps in incomes and in access to services. This will require mobilizing additional revenues and improving service delivery. The case for more progressive taxation, reversing the decline of the past decades, has increased as a result of the pandemic. A possible option is a COVID-19 recovery contribution (Klemm et al., 2021)_levied, for example, as a progressive surcharge on personal incomes for those at the high end of the income scale-so that those who can afford to pay more make a bigger contribution to the recovery effort.

Considering our results together with those of previous papers summarized above, a tentative interpretation could be as follows. People who have been harmed by the pandemic currently demand more redistributive policies. If such demand is not met, they may grow disillusioned and lose trust in the government. Thus, the stakes are high for policymakers to deliver both on the health front and on policies that foster more inclusive economic growth. 


\section{Appendix}

\section{Screener}

- What is your gender?

$\square$ Male $\square$ Female $\square$ Other/nonbinary

- What is your age?

- What was your pretax household income last year?

$\square$ Below $\$ 20,000 \square \$ 20,001-\$ 40,000 \square \$ 40,001-\$ 50,000 \square \$ 50,000-\$ 75,000$

$\square \$ 75,001-\$ 100,000 \square \$ 100,000-\$ 150,000 \square$ more than $\$ 150,000$

- What's the zip code of where you live in?

\section{Introductory Paragraph}

The COVID-19 pandemic has caused the government to spend more to cover health costs and help people and businesses. Meanwhile, tax revenues have fallen because of the decline in incomes.

After the pandemic, a combination of spending cuts and tax increases is to be expected. We would like to get your input on how the government should approach making these changes.

For the following two questions each respondent obtains randomly one of the following terms where the questions says "CELL WORDING":
(i) $\operatorname{tax}$
(ii) solidarity tax
(iii) COVID-19 recovery tax
(iv) contribution
(v) solidarity contribution
(vi) COVID-19 recovery contribution

\section{Questions}

1. Would you support the introduction of a temporary [CELL WORDING] charged on those who are well off, to cover the costs of fighting the COVID-19 pandemic and its economic impact?
a. Yes.

b. No.

2. Assuming such a temporary [CELL WORDING] were introduced, which of the following would you support? (Choose all that apply)
a. Charged on people with high incomes
b. Charged on people with high incomes as a result of the pandemic
c. Charged on people with high wealth
d. Charged on companies with high profits
e. Charged on companies with high profits as a result of the pandemic
f. Charged on everyone, in proportion to their income
g. None-I would not support a temporary [CELL WORDING]

We'd now like to shift from temporary changes to the tax system to permanent or structural changes. 
3. Would you support a permanent increase in taxes raised only on those who are well off? (Choose all that apply)
a. Yes, for greater social spending / to fight poverty.
b. Yes, for improving infrastructure (roads, bridges, etc.).
c. Yes, for funding schools and education.
d. Yes, for a cleaner environment in my state.
e. Yes, to reduce the national debt.
f. Yes, if spent in my geographical region.
g. Yes, to fight climate change.
h. Yes, for other reasons [SPECIFY]
i. No.

4. Would you support a tax law change that raises taxes on the rich, reducing them for everybody else so that the government receives the same total revenue? (Choose all that apply)
a. Yes, if the tax increase is on the richest $1 \%$.
b. Yes, if the tax increase is on the richest $10 \%$.
c. Yes, if the tax increase is on the richest third.
d. Yes, if the tax increase is on the richer half.
e. Yes, if the tax increase is on multinational corporations.
f. No.

5. Which of the following statements do you agree with the most? (Choose one)
a. Taxes are generally too high.
b. Taxes are about right.
c. Taxes are generally too low.

$5 \mathrm{~b}$. Which of the following statements would you agree with? (Choose all that apply)
a. The rich in this country do not pay their fair share of taxes.
b. Our society needs more solidarity.
c. Most tax revenues are squandered anyway.
d. The national debt is a worry.
e. The poor will never work if benefits are too generous.
f. None of the above

6. Would you favor more or less government spending for the following? (At least one needs to be "less")

$\begin{array}{lccc} & \text { More } & \text { No change } & \text { Less } \\ \text { Health care } & \square & \square & \square \\ \text { Education } & \square & \square & \square \\ \text { Cleaner environment in your area } & \square & \square & \square \\ \text { Fighting climate change } & \square & \square & \square \\ \text { Police } & \square & \square & \square \\ \text { Military } & \square & \square & \square \\ \text { Border Protection } & \square & \square & \square \\ \text { Infrastructure (for example, roads, } & \square & \square & \square \\ \text { electricity) } & & & \end{array}$


7. Who has, in your opinion, suffered the most during the pandemic? (choose all the apply)
a. Everyone has suffered about equally
b. Poor people
c. The middle class
d. Rich people
e. Young people
f. Old people
g. People in specific sectors (hospitality, tourism, etc.)
h. Minorities
i. Women

8. How has the COVID-19 pandemic directly affected your life? (Click all that apply)
a. I or someone in my household has lost employment
b. Someone I know has lost employment
c. I or someone in my household became seriously ill with COVID-19
d. Someone I know became seriously ill with COVID-19
e. There has been no direct impact on my household
f. There has been an increase in my household's income

13. How many children do you have? [RANGE 0-9]

14. Including yourself, how many people live in your household?
a. Adults:
b. Children (18 or younger):

15. What is your highest level of education?
a. High school not completed
b. High school completed
c. College degree
d. Graduate school degree
e. Prefer not to answer

16. How would you describe your ethnicity?
a. European American/White
b. African American/Black
c. Hispanic/Latino
d. Asian/Asian American
e. Mixed
f. Other
g. Prefer not to answer 
Supplementary Information The online version contains supplementary material available at https://doi. org/10.1007/s10797-021-09700-2.

Acknowledgement We are grateful to Zhiyong An, Olivier Basdevant, Barry Eichengreen, Ben Enke, Jean-Marc Fournier, Katja Funke, Elizabeth Gavin, Nikolay Gueorguiev, Shafik Hebous, Daniel Leigh, Miguel Pecho, Ippei Shibata, Antonio Spilimbergo, Genet Zinabou, participants in seminars at the IMF, the editor, and two anonymous referees for helpful suggestions. The views expressed in this paper are those of the authors and do not necessarily represent the views of the IMF, its Executive Board, or IMF management.

\section{References}

Aksoy, C. G., Eichengreen, B., \& Saka, O. (2020). The Political Scar of Epidemics. NBER Working Paper 27401.

Alesina, A., \& Giuliano, P. (2009). Preferences for redistribution. In J. Benhabib, M. O. Jackson, \& A. Bisin (Eds.), Handbook of Social Economics (Vol. 1A, pp. 93-131). North-Holland.

Alford, J. R., Funk, C. L., \& Hibbing, J. R. (2005). Are political orientations genetically transmitted? American Political Science Review, 99, 153-167.

Alford, J. R., Funk, C. L., \& Hibbing, J. R. (2008). Beyond liberals and conservatives to political genotypes and phenotypes. Perspectives on Politics, 6(2), 321-328.

Dahlberg, M., Edmark, K., \& Lundqvist, H. (2012). Ethnic diversity and preferences for redistribution. Journal of Political Economy, 120(1), 41-76.

Di Tella, R., Galiani, S. F., \& Schargrodsky, E. S. (2007). The formation of beliefs: Evidence from the allocation of land titles to squatters. Quarterly Journal of Economics, 122(1).

Enke, B. (2020). Moral values and voting. Journal of Political Economy, 128(10), 3679-3729.

Enke, B., Rodríguez-Padilla, R., \& Zimmermann, F. (2020). Moral Universalism and the Structure of Ideology. NBER WP 27511.

Forenmy, D., Sorribas-Navarro, P., \& Castelló, J. V. (2020). Living at the peak: health and public finance during the COVID-19 pandemic. Universitat de Barcelona Institut d'Economia de Barcelona.

Gideon, M. (2017). Do individuals perceive income tax rates correctly? Public Finance Review, 45(1), 97-117.

Giuliano, P., \& Spilimbergo, A. (2014). Growing up in a recession. Review of Economic Studies, 81, 787-817.

Haidt, J. (2012). The righteous mind. Vintage Books.

Hatemi, P. K., Gillespie, N. A., Eaves, L. J., Maher, B. S., Webb, B. T., Heath, A. C., Medland, S. E., Smyth, D. C., Beeby, H. N., Gordon, S. D., Montgomery, G. W., Zhu, G., Byrne, E. M., \& Martin, N. G. (2011). A genome-wide analysis for liberal and conservative political attitudes. Journal of Politics, 73, 271-285.

Hennighausen, T., \& Heinemann, F. (2014). Don't tax me? Determinants of individual attitudes toward progressive taxation. German Economic Review, 16(3), 255-289.

International Monetary Fund (2021), A Fair Shot, IMF Fiscal Monitor, April.

Jost, J. T., Glaser, J., Kruglanski, A. W., \& Sulloway, F. J. (2003). Political conservatism as motivated social cognition. Psychological Bulletin, 129, 339-375.

Kennedy, C, Lopez, J, Keeter, S, Lau, A, Hatley, N and Bertoni, N, (2021) Confronting 2016 and 2020 Polling Limitations, Pew Research Center.

Klemm, A, Hebous, S, Michielse, G, and Nersesyan, N (2021) COVID-19 Recovery Contributions, IMF Special Series on COVID-19.

Luttmer, E. F. P., \& Singhal, M. (2011). Culture, context, and the taste for redistribution. American Economic Journal Economic Policy, 3, 157-179.

Margalit, Y. M. (2013). Explaining social policy preferences: evidence from the great recession. American Political Science Review, 107(1), 80-103.

Rees-Jones, A, D’Attoma, J, Piolatto, A, Salvadori, L (2020) COVID-19 changed tastes for safety-net programs, NBER Working Paper No. 27865. 
Stantcheva, S (2020) Understanding tax policy: How do people reason? NBER Working Paper 27699.

Publisher's Note Springer Nature remains neutral with regard to jurisdictional claims in published maps and institutional affiliations. 